\title{
ON THE ECCENTRICALLY LOADED SOCKET FOOTINGS WITH CUT - OFF PYRAMID SHAPED SOCKET
}

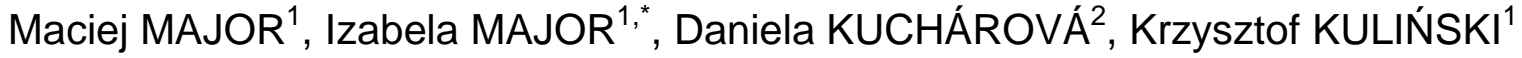 \\ ${ }^{1}$ Faculty of Civil Engineering, Czestochowa University of Technology, ul. Akademicka 3, 42-200 \\ Częstochowa, Poland. \\ 2 Faculty of Civil Engineering, University of Žilina, Univerzitná 8215/1, 01026 Žilina, Slovakia. \\ corresponding author: imajor@bud.pcz.czest.pl.
}

\begin{abstract}
In this work considerations concerning eccentrically loaded socket footing with cut-off pyramid shaped socket were presented. As an object of study sloped footing with $1.40 \mathrm{~m}$ height, corresponding to the maximum frost depth has been adopted. Knowing that in practice there are no perfect pure axial loads, load applied on the eccentricity has been taken into considerations. Eccentric loads result in footing rotation in the direction of eccentricity and acting load, hence one footing end is imbedding into the ground, whereas second end tries to rise up. To observe that phenomenon, elastic type of support under the foundation was introduced corresponding to the naturally humid sand with medium compaction. Presented in this paper considerations of innovative connection technology between footing and column were based on performed numerical studies. Advantages and disadvantages of presented footing in comparison to normal socket footings solutions were widely discussed. Numerical analyses were performed with the utilization Finite Element Method based SolidWorks software.
\end{abstract}

\section{Keywords:}

Socked footing; FEM; Eccentric load; Mises stress.

\section{Introduction}

Foundations as well as footings are buildings or any engineering objects fundamental structures, on which mainly compressive forces from above arisen structures are being transferred. Depending on both structure weight and transferred loads following types of foundations may be indicated:

- shallow foundations - (continuous and spread footings, slab-on-grade foundation) lightweight structures or/and high load bearing capacity soils,

- deep foundations - (impact driven and helical piles, caissons, drilled shafts, geo-piers) heavyweight constructions or/and outer low load bearing capacity soils,

- monopiles - (large-diameter foundations) all types of loading transferred onto the ground, in example: chimneys.

Through the centuries, the role of foundations has changed in only small manner. At the beginning, around twelve thousand years BC, first utilized wooden piles served as a protection from wild animals - people built their houses onto the shallow waters in order to protect themselves from animals as well as from dangerous neighbours. In subsequent years, people discovered that buildings may also be settled onto stones, especially heavyweight constructions such as pyramids and ancient Greece constructions were settled onto large stones which prevented ground subsidence. One of the most important discoveries in the history of foundations utilization was discovery of cement by the ancient Romans. The cement invention lead to great ease of foundation casting and by the same token provided construction stability even greater than with the utilization of only stones. Wide historical review of building foundations has been presented in [1]. 
After years due to rapid technological development, in the 20th and 21th century design of foundations has been standardized. Recently, in the European standards [2,3] there are many common conditions, which should be met in order to properly design the foundation. In the literature [2 - 5] may be found many common rules for designing foundations, however there is lack of information concerning utilization of different foundations shapes and different socket foundation solutions. With such complex solutions often classic mathematical approach or Finite Element Method (FEM) based software have to be utilized [6,7]. Moreover, utilization of FEM allows to observe phenomena such as: cracking, failure, stress distribution, rheological effects etc. both in micro and macro scale. Numerical analysis concerning different footings, loadings and soil conditions were performed by many researchers. Reliability bearing capacity of a strip footing located onto slope crest built of cohesive soil using the random finite element method was the subject of interest in [8]. It was proved that variation coefficient as well as soil cohesion spatial correlation length has significant influence onto bearing capacity. Moreover, the influence of mentioned parameters was higher with the increased slope height in comparison to the footing width ratios. Soft computing methods to predict the strip footing bearing capacity were used in [9]. Authors used several soft-computing models: feedforward neural network (FFNN), radial basis neural network (RBNN), general regression neural network (GRNN), support vector machine (SVM), tree regression fitting model (TREE) and adaptive neuro-fuzzy inference system (ANFIS). Example numerical analyses concerning the bearing capacity for different footings and ground conditions may also be found in [10 - 13]. It is worth noting that FEM not only applies in mechanics and soil mechanics, but can also be used in medicine, physics, product enhancement etc. As an example, authors in $[14,15]$ used FEM to predict how the impact wave transfers energy through the proposed innovative concrete-rubber building materials.

In literature can be found that the loads applied onto footings are often axial loadings, which result in uniform stress distribution under foundations base. Hence, obtained results are insufficient from the practice point of view, because many footings especially located on the external structure outline are also subjected to the eccentric type of loading. Circular/ring footings subjected to the eccentric load were the subject of interest in $[16,17]$. Through the analysis performed in [16] one may notice, that the bearing capacity ratio is enhanced with increased eccentricity in the direction to the core boundary of footing, whereas with further eccentricity increase the ratio decreases. In [17] authors performed numerical analyses of large-diameter ring foundations under chimneys subjected to the eccentric loading. It was shown that for the load inclination of $0-15^{\circ}$ the ultimate load of footing is decreased by $41-52 \%$ for unreinforced soil, whereas for reinforced soil decrease fit in range of $19-22 \%$.

According to the fact, that there is small number of publications concerning new types of socket foundations solutions, in this paper new innovative solution of footing with cut-off pyramid ended socket was proposed. In order to provide more practical meaning of presented solution, for the numerical analysis sloped socket footing located onto naturally wet sand ground was adopted. Moreover, knowing that in practice there are no pure axial loading, footing subjected to load placed on eccentricity has been taken into considerations. As numerical software - SolidWorks fully based on finite element method has been chosen. Through the analysis the main priority was to prove that the proposed solution of cut-off pyramid ended column connected with similar shape ended socket have greater advantages than the standard planar plane ended socket foundations. It has been preliminarily assumed that in case of axial load proposed shape of connection should distribute normal axial force into the stretching force acting perpendicularly to the column longitudinal axis. In result such force could be transferred onto the reinforcement from steel rods. Moreover, it could become possible to decrease the height of foundation in comparison to the standard socket footing.

\section{The object of study}

The object of study comprises of innovative solution - sloped socket footing with cut-off pyramid ended socket. As an initial model, footing with square base was adopted with dimensions of $2.50 \times 2.50 \mathrm{~m}$. Square plane was extruded by $0.60 \mathrm{~m}$ in the direction of $Z$-axis. Second square plane with the outline dimensions $1.00 \times 1.00 \mathrm{~m}$ was distanced by $1.40 \mathrm{~m}$ from the footing base in the positive $Z$-axis direction. Adopted height of foundation equal $1.40 \mathrm{~m}$ was assumed on the basis of [3] as the highest freezing depth in Poland. From the level of $0.60 \mathrm{~m}$ measuring from the foundation base, the body of foundation was extruded upwards with inward incline angle to connect with the $1.00 \times 1.00 \mathrm{~m}$ square plane. In the mid-point of top surface of discussed foundation, a square cross- 
section socket was formed via special steel form. The outline steel form dimensions were assumed as $0.42 \times 0.42 \mathrm{~m}$ and the form thickness as $10 \mathrm{~mm}$. Each external vertical edge of prism was chamfered by $20 \mathrm{~mm}$ with $45^{\circ}$ angle. The form which was assumed to strengthen the connection between foundation and column as well as to prevent concrete cracking at the joint was assumed in a shape of prism with cut-off pyramid end. Viewing from the top foundation surface, the socket had following dimensions: square of $0.42 \times 0.42 \mathrm{~m}$ was extruded by $0.50 \mathrm{~m}$ in the negative $Z$-axis direction, then the created bottom surface was furtherly extruded by $0.25 \mathrm{~m}$ with inward incline angle equal $30^{\circ}$ measuring from the vertical line corresponding to the prism outline to the external inclined surface of steel form.

For the adopted model of foundation, a section of square cross-section column has also been adopted. The cross-section outline dimensions were $0.40 \times 0.40 \mathrm{~m}$. Total column length was assumed as $1.20 \mathrm{~m}$. At the connection location, column has also been reinforced with steel form to prevent concrete cracking under eccentricity load. The external outline reinforcing steel form dimension was assumed as exactly the same as columns external outline. Hence, the form would be the extension of assumed column. Moreover, column's connection end, was also assumed as cut-off pyramid, however, the length of cut-off pyramid was assumed as $0.20 \mathrm{~m}$ in order to leave a small gap between two reinforcing forms providing forces distribution only through inclined form walls. According to that, smaller amount of axial compressive force from column would be transferred onto the ground. Socket footing, column and the reinforcement forms were presented in Fig. 1.

For the analysis it was assumed that the foundation and column were made of C20/25 class concrete, whereas reinforcement forms would be casted from S235JR grade steel. It was assumed that on the section of column acts compressive force with value of $500 \mathrm{kN}$. Different values of force eccentricity were taken into considerations i.e. $0 ; 0.20 ; 0.40 ; 0.60$ and $0.80 \mathrm{~m}$, respectively.

It should be noted that for the numerical analysis special grip elements located onto both foundation and column steel form reinforcements have been neglected as seen in Fig. 1. In practice small rebars could be welded onto exterior footing reinforcement form in order to provide its greater stability in footing. In the column reinforcement form, one could weld rebar to the bottom saddle with welded rebar insets or small rebars could be welded in the inner side of the form.

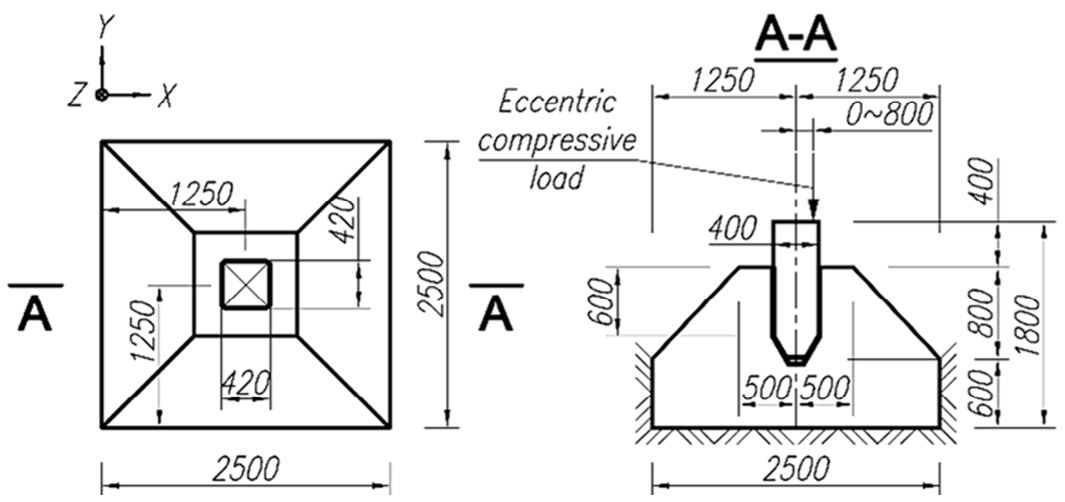

\section{Footing Column reinforcement reinforcement}
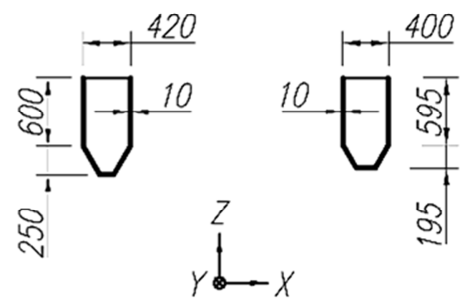

Fig. 1: Concrete sloped footing with cut-off pyramid ended socket strengthened with steel forms.

Footing subjected to compressive eccentric load.

For the numerical analysis presented in Fig. 1 socket footing was modelled in SolidWorks finite element method based software. Both concrete and steel materials were assumed as elastic/isotropic. For $\mathrm{C} 20 / 25$ class concrete maximum compressive strength was declared as $20 \mathrm{MPa}$ and tensile strength as $1.715 \mathrm{MPa}$, whereas for S235JR grade steel material yield stress was declared as $235 \mathrm{MPa}$. Young modulus in case of concrete was set as $32 \mathrm{GPa}$ and the Poisson's ratio as 0.2 , whereas for steel $E=210 \mathrm{GPa}$ and $v=0.3$, respectively. Load was applied as concentrated force acting in a negative constant direction along $Z$-axis and distributed directly onto the top surface of the column. Assumed value of load was set as $500 \mathrm{kN}$. Five different values of load eccentricity have been taken into considerations: from 0 up to $800 \mathrm{~mm}$ with $200 \mathrm{~mm}$ step.

As a soil layer, medium grain sand with infinite depth has been assumed. Ground water level has been omitted in the analysis. On the basis of above, as a footing boundary conditions elastic type of support has been adopted. Elastic spring was assumed under the footing base and on the external vertical surfaces of base extrusion (sees Fig. 1). Pressure from soil located over the footing slopes has been neglected. Due to the fact that the naturally wet, medium compacted sand was adopted to the 
analysis, the elastic support spring stiffness coefficient on the basis of Autodesk Robot soil calculator in the normal direction was assumed as $37.810 \mathrm{MN} / \mathrm{m}^{3}$.

Knowing that the connection of footing reinforcement form with the foundation could be realised via small welded rebars and connection of concrete column with steel form could be realized in similar manner in order to simplify the numerical model, bonded contact for these connections have been used. Contact between both steel reinforcing forms should allow the vertical movement along $Z$-axis, thus contact without penetration has been used for all inner surfaces of foundation steel reinforcement and all external surfaces of columns' reinforcement, respectively. Friction between steel plates was declared as 0.15 , which correspond to the static friction between steel elements. Discretization of model volume has been performed with the 3-D Solid tetrahedron elements. Size of elements varied between $5-50 \mathrm{~mm}$. Smaller size elements were used near the connection area. Total number of 71187 finite elements was used to represent the model.

\section{Numerical results}

As the object of study comprised of new socket footing solution, it was interesting if forces distribution in the connection between footing and column provides lower stresses under the footing base in comparison to the typical socket footing. According to that height in the proposed foundation could be lowered while keeping the same stress under the base as in normal socket footing. Comparison of maximum Mises stress (MHM stress) under the typical and proposed sloped socket footing base for different values of load eccentricity was presented in Fig. 2. For a better clearance of MHM stress distribution for both footings, isovolumes with limited minimum stress to $0.15 \mathrm{MPa}$ for load eccentricity $e=0$ were presented in Fig. 3 .

On the basis of Fig. 2 it was clearly visible that for the whole range of load eccentricity, values of obtained MHM stress in footing with pyramid ended socket was lower than for its counterpart with planar ended socket. In the planar ended socket footing, values of MHM stress under the base with the increased value of eccentricity were lowered. It was connected with the stress distribution in the footing - footings' base bends under the compressive force, whereas acting in the model momentum results in imbedding of one of footing base edges into the ground. The greater the momentum, the greater the value of stress from edge imbedding. Despite that in presented cases value of MHM stress due to edge imbedding was still lower than from base pressure area located under the column compressive force gave greater results. It should be noted there that further increase of eccentricity value (over presented values), would result in increased value of stress in the standard type of socket footing.

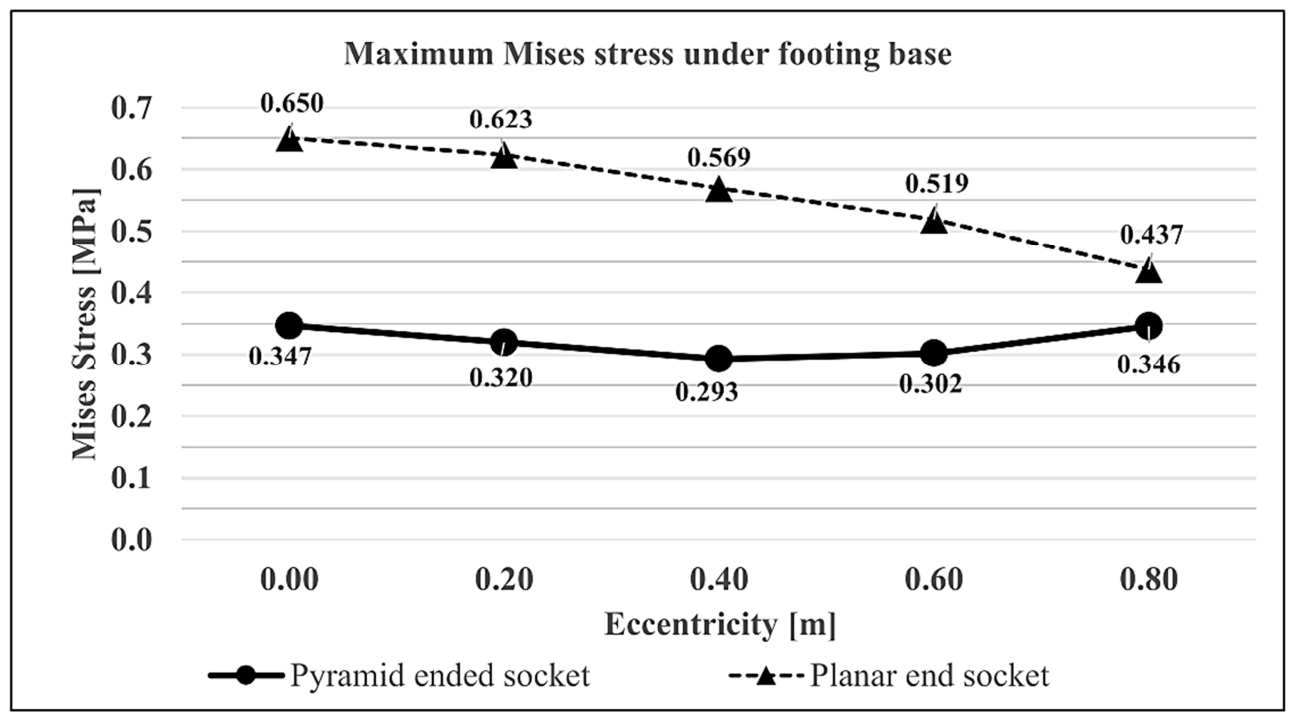

Fig. 2: Comparison of MHM stress under footing bases for solution with pyramid and planar ended socket at different values of load eccentricity. 
a)

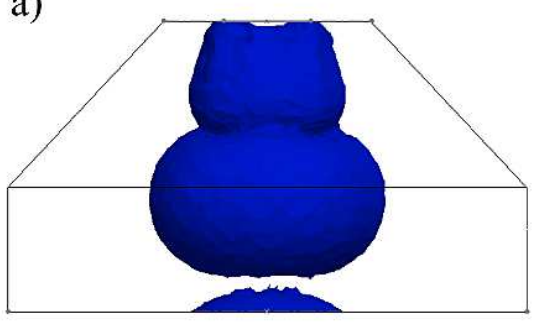

b)

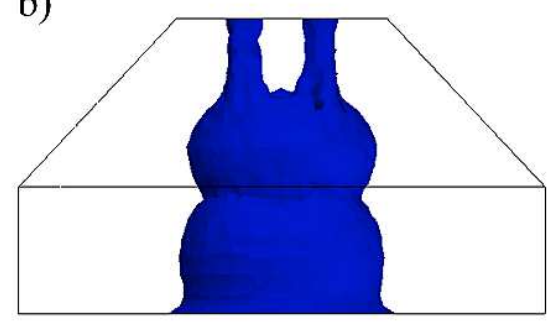

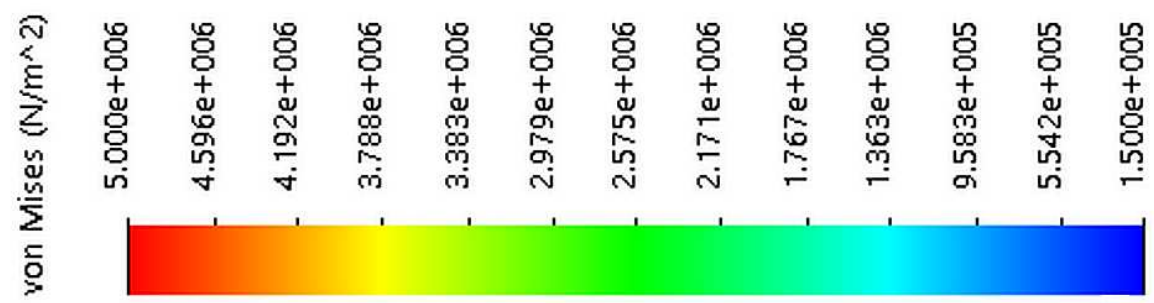

Fig. 3: Comparison of MHM stress distribution in footings with: a) pyramid ended socket, b) planar ended socket. Load eccentricity $e=0 \mathrm{~m}$. Minimum value of presented stress limited to $0.15 \mathrm{MPa}$.

Significant influence of one footings' edge imbedding could be observed in the footing with the pyramid ended socket. Considering the course of pyramid ended socket footing curve from Fig. 2 it was clearly visible that with eccentricity greater than $e>0.40 \mathrm{~m}$, maximum MHM stress under footing becomes greater. At the beginning with the increased value of eccentricity, value of maximum Mises stress decreases and the maximum was located nearly the mid-point of footing base. With eccentricity of $0.60 \mathrm{~m}$ and $0.80 \mathrm{~m}$, maximum stress was located under the one of footing's edge - the one which was located in the same direction as eccentricity, i.e. edge perpendicular to the eccentricity line extrusion. Presented in Fig. 3 stress distribution in the footings subjected to pure axial loading, unequivocally prove, that in the pyramid ended socket footing (see Fig. 3a) some amount of compressive force from the column was transformed into the stretching force and in comparison to planar ended socket footing (Fig. 3b) lower amount of compressive force was transferred onto the ground. According to that pyramid-ended socket footing would require a bit more rebar reinforcement than the socket footing with planar end.

In Fig. 4 MHM stress in the following parts of socket footings was presented: column, columns' and footings' steel strengthening form and concrete covering the footing socket form. Stress was presented as maximum values obtained in particular foundation parts. On the basis of Fig. 4 one can observe that in the whole range of load eccentricity maximum MHM stress increases. It should be noted that slight stress increase in the range of eccentricity 0 to $0.20 \mathrm{~m}$ was connected with the acting force located not far away from the columns' core cross-section. According to that, only small amount of compressive force was transformed into bending momentum. With eccentricity greater than $0.20 \mathrm{~m}$ it could be observed that the stress in the column, columns' form and in concrete under the footing strengthening form rapidly and linearly increased. Only in columns' steel form in the whole considered range of force eccentricity, the MHM stress increased by around $50 \%$ from 24.51 up to $35.12 \mathrm{MPa}$. In case of columns' strengthening form, maximum Mises stress was obtained onto the external corners of transitions between its vertical and sloped shape. 


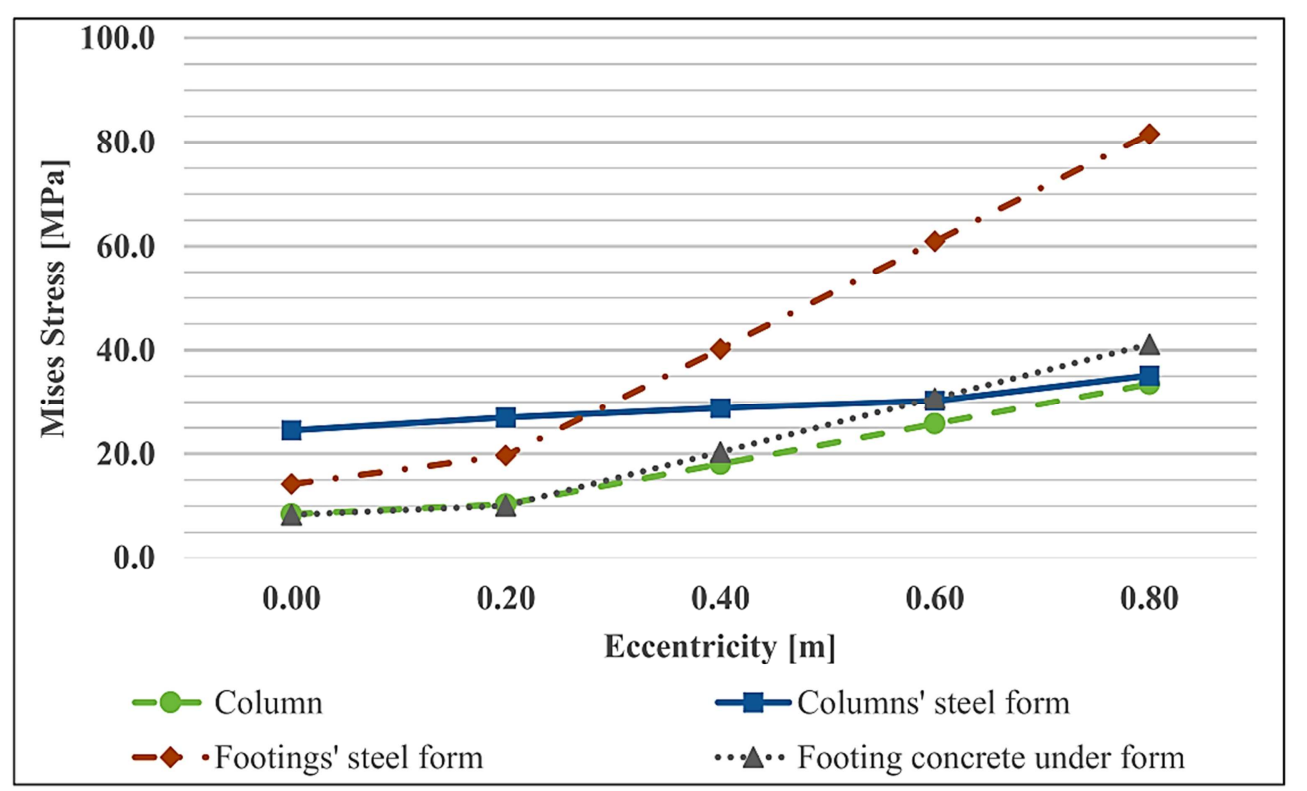

Fig. 4: Maximum MHM stress in the particular elements of proposed socket footing subjected to compressive load with value of $500 \mathrm{kN}$ for different load eccentricity values.

What's the most important from Fig. 4, with eccentricity greater than $0.40 \mathrm{~m}$, in the concrete under the footings' steel form reinforcement stresses exceed the maximum value of assumed C20/25 concrete class. According to that concrete cracking could have occurred under the steel form. Moreover, on the top footing surface also with eccentricity value greater than $0.40 \mathrm{~m}$, concrete cracking could be observed near the strengthening steel form for assumed value of loading equal $500 \mathrm{kN}$. The smaller the load, the lower the stresses would be obtained. In case of eccentricities greater than $0.40 \mathrm{~m}$ with remaining applied load, higher concrete class should have been utilized. As a second possibility could be provided a special cage from rebars near the connection between column and footing.

Graph presenting maximum imbedding of footing edge located onto the direction of eccentricity and perpendicular to that eccentricity (described as Edge "A") and rise-up of opposite footing edge (denoted as Edge "B) was presented in Fig. 5. Minus sign denotes displacement in the opposite direction to the $Z$-axis direction. As discussed in Eurocode standard [3] maximum of $1 / 3$ of width dimension of footings' base rise-up can be allowed, thus $2 / 3$ of footings' base should have been imbedded into the ground. According to that, and considering the rise-ups and imbedding from Fig. 5 one may notice that even for the load eccentricity equal $0.80 \mathrm{~m}$ the Eurocode condition has been met. Allowable in presented case rise-up could cover $0.833 \mathrm{~m}$ of footings' width, whereas for the eccentricity $e=0.80 \mathrm{~m}$ footings' base rise-up covered around $0.58 \mathrm{~m}$ of footings' width.

Maximum clockwise rotation of presented foundation was equal $0.181^{\circ}$, measuring from the horizontal line, crossing through the point which was neither imbedded nor raised. As observed with small values of eccentricity $e<0.40$ m only imbedding was observed, which from the engineering point of view was the best case. Considering the course of curve from Fig. 2 for footing with pyramid ended socket it was clearly visible that the lowest MHM stress under the footing base was obtained for eccentricity equal $0.40 \mathrm{~m}$, which was connected with the boundary conditions adopted. Elastic spring not only prevented the footing base of imbedding but also prevented the movement of foundation in the $X$ and $Y$-axis direction through springs applied onto vertical surfaces of analysed footing (see Fig. 1.). In practice soil covering the foundation to a certain extent prevents some horizontal foundation movement. Foundation rotation and stress distribution under the footings' base for $e=$ $0.80 \mathrm{~m}$ was presented in Fig. 6 . 


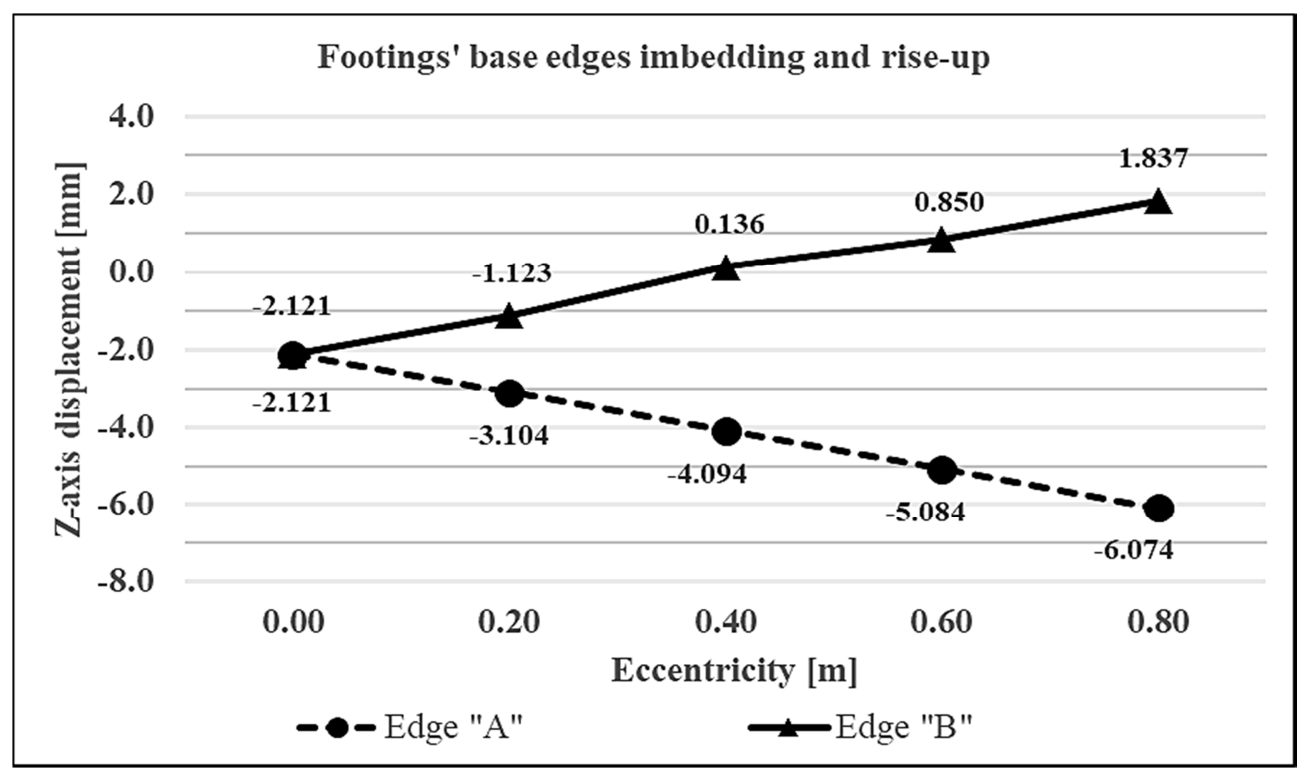

Fig. 5: Maximum imbedding and rise-up along $Z$-axis of footing with pyramid ended shape socket base edges. Footing subjected to static load with different values of eccentricity.

a)

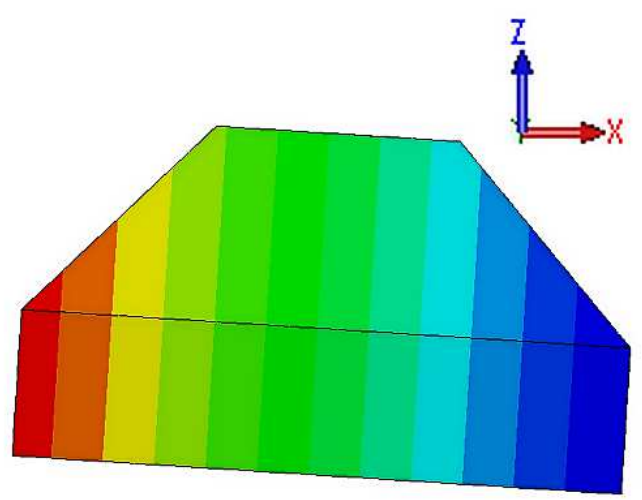

b)

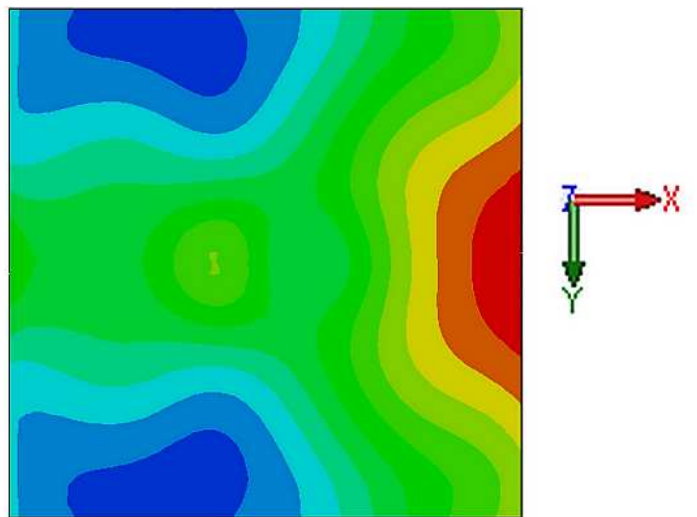

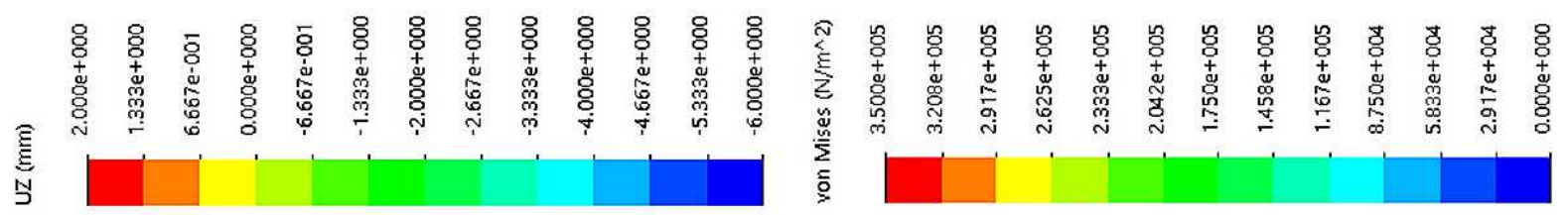

Fig. 6: Numerical results of: a) foundation scaled rotation with imbedding/rise-up plot, b) MHM stress distribution under the proposed socket footing. Other parameters: $e=0.80 \mathrm{~m}$.

As previously discussed, in Fig. $6 \mathrm{~b}$ it was clearly visible that the higher stress values were obtained near one of the footings' edge, whereas on the second edge which was risen-up values were significantly smaller. Moreover, near the centre area of footing base, one may notice a small stress increase, which was a result of transferred compressive load from the column. Area on the right side presents the increase of stress connected with edge imbedding due to load applied on eccentricity. That increase was also connected with the elastic springs representing the soil covering the foundation and preventing the movement along $X$ and $Y$-axis.

\section{Optimization analysis}

Previously presented and discussed stresses in the footing with pyramid ended socket in comparison to typical socket footing solution leave a space for further modifications in analyzed project. First of all, according to the data presented in Fig. 2 one may notice, that for the proposed footing with pyramid ended socket, height of foundation could be reduced, while keeping the same 
value of stress under the base as in typical socket footing. In order to optimize the height of foundation it was assumed that the pure axial loading is acting onto the column, with exactly same value of $500 \mathrm{kN}$. It should be noted, that despite the footing height reduction the total height of socket in order to provide appropriate column support was assumed as $0.80 \mathrm{~m}$. Space between the bottom surface of foundation and end-point of pyramid ended socket should not be lower than $0.15 \mathrm{~m}$ in order to provide good reinforcement coverage (minimum rods coverage from top and bottom in the most demanding conditions according to [2]). Moreover, it was checked if for pure axial loading, width dimensions could be decreased in order to reduce the footing weight. For the optimization process it was assumed that the height of foundation may change with the $0.02 \mathrm{~m}$ step, whereas footing width dimensions were changed with $0.05 \mathrm{~m}$ step, respectively. It was assumed that both footings' width dimensions were modified simultaneously. Additionally, it was assumed that for the width optimization analysis, width dimensions cannot be lower than $1.00 \mathrm{~m}$ in order to provide appropriate coverage for rods and appropriate columns' support.

In the second case, footing base dimensions were modified to counteract the effect of load eccentricity, reduce the influence of external footings' edges rise-up and imbedding for load eccentricity $e=0.80 \mathrm{~m}$. For the optimization analysis it was assumed that the top surface of the foundation remains in same place, however external wall in the direction of eccentricity (along $X$-axis), located onto $Y Z$ plane (see. Fig. 1) was extruded with $0.10 \mathrm{~m}$ step. For the discussed analysis special SolidWorks optimization module was used. Modified dimensions through the optimization process were shown in Fig. 7.

\section{a) Height optimization model}

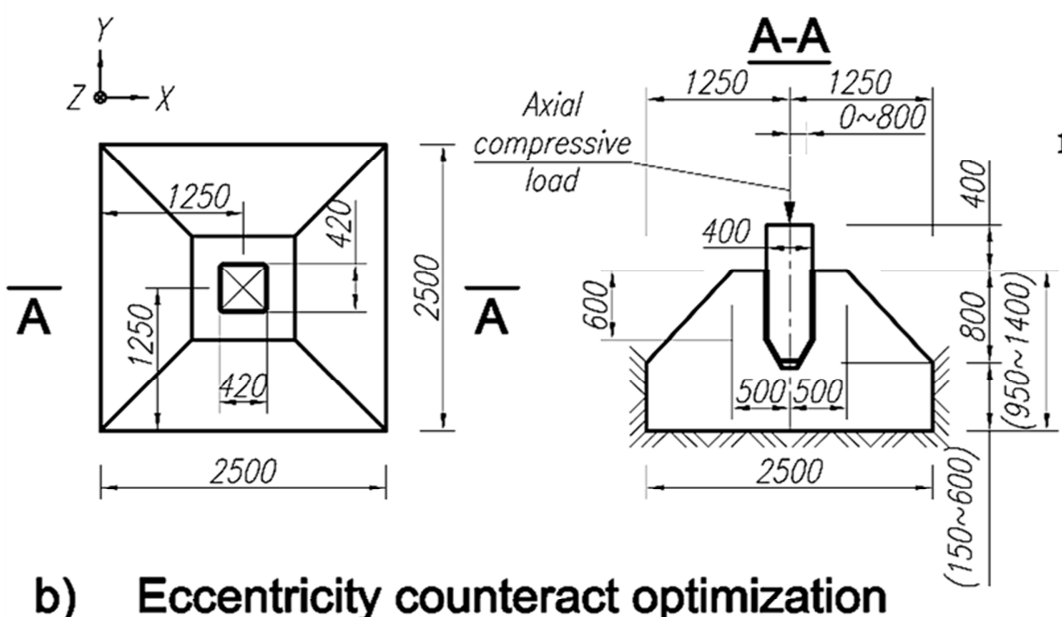

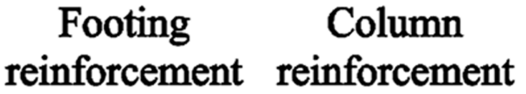

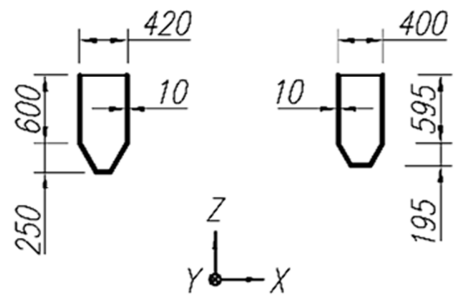

A-A

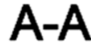

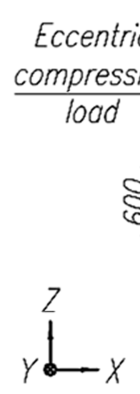

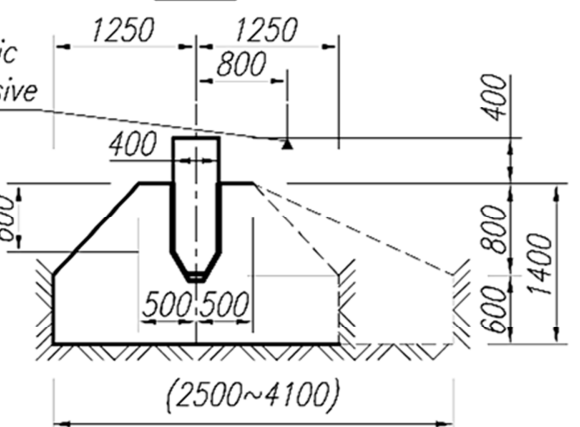

Fig. 7: Changes in dimensions in the optimization analysis for: a) foundation height reduction, b) counteracting the effect of load eccentricity. Modified dimensions presented in parentheses.

First of all, footing with pyramid ended socket subjected to pure axial loading height and width dimensions' optimization has been performed. At first, height dimension was reduced in order to obtain nearly same value of Mises stress under the foundation bottom base and then another optimization of foundation width dimensions was performed. According to the fact, that two different optimization analyzes were performed it became possible to find the point for which width and height of foundation could be reduced to obtain lower/same stress under footing base as for typical socket footing. Footing dimensions' optimization and its influence on MHM stress under the base was presented in Fig. 8. 
Comparing results for footing height optimization it could be observed that for total height of $1.15 \mathrm{~m}, \mathrm{MHM}$ stress results were nearly the same as for typical socket footing for which $0.650 \mathrm{MPa}$ was determined according to Fig. 2. Greater reduction of height dimension led to higher stresses under the footing base. In the second case, decreasing both footing width dimensions showed that maximum Mises stress under the footing base was not exceeded in the whole range of analyzed footings' width dimensions. Comparison of these two lines presented in Fig. 8 allows to vicariously predict how both footing area and height can be reduced to obtain approximate value of demanded MHM stress. It should be noted that presented results concerned only pure axial loading, thus for eccentricity further optimizations should have been carried out.

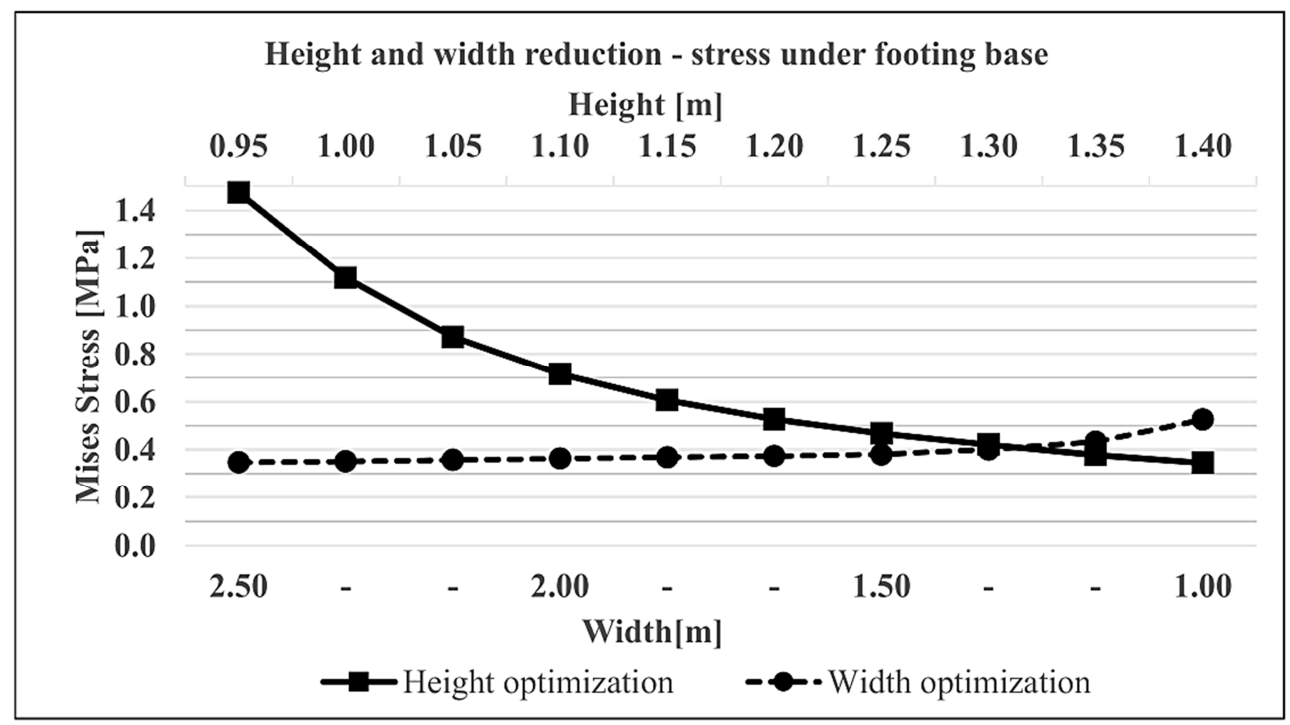

Fig. 8: Influence of footing width (dashed line) and height (solid line) reduction onto obtained Mises stress under the footing base.

In the second case, eccentricity counteracting optimization for load equal $500 \mathrm{kN}$ and eccentricity $e=0.80$ was performed. The influence of YZ-plane footing surface extrusion in the direction of loading eccentricity (see Fig. 7) was presented in Fig. 9. Mises stress was presented with dot line, whereas external edge imbedding/rise up by solid/dash line, respectively.

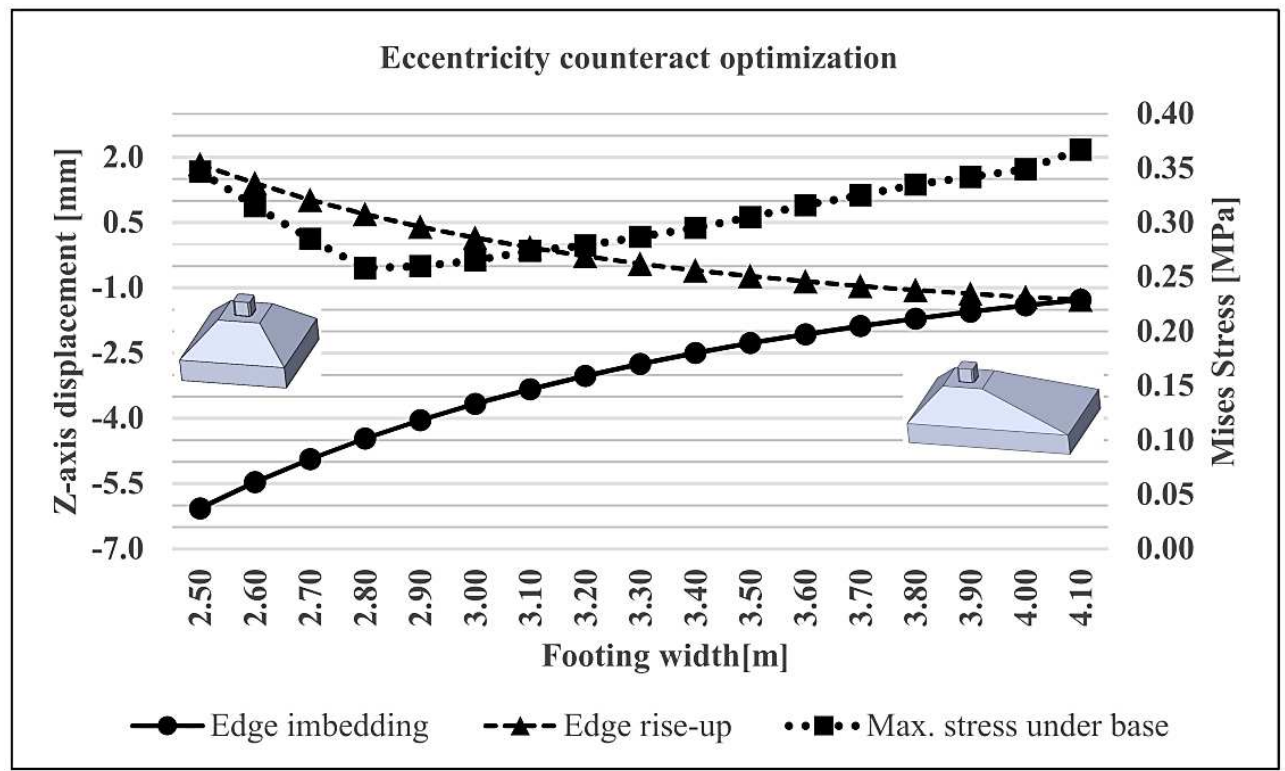

Fig. 9: Influence of footing width extrusion on the Mises stress under the base and external edge imbedding/rise up. Compressive load of $500 \mathrm{kN}$ applied on eccentricity $e=0.80 \mathrm{~m}$. 
Through the optimization analysis it was shown that increasing one of the footing dimension the one in parallel direction as line of load eccentricity, while perpendicular dimension to that line remaining the same it was possible to totally remove the effect of eccentricity (footing rotation). As presented in Fig. 9 the longer the width dimension of footing, the lower footing rotation could be obtained. With width value equal $3.10 \mathrm{~m}$ it was possible to make both external footing edges imbedding, whereas at $4.10 \mathrm{~m}$ of footing width, effect of eccentricity was totally removed - both external edges were equally imbedded. Despite fact that equal imbedding of footing external edges could be achieved, stress under the footing base decreased only in small range. Only for $0.30 \mathrm{~m}$ of footings' width extrusion obtained stresses became lower, while for further width extrusion stress almost linearly increases (see dot line in Fig. 9). Mentioned behavior was connected with the increased weight of footing as well as lower possibility of footing rotation.

Hence, in the footing design there are many various parameters which should have been taken into account i.e. footing dimensions, shape; load type, its value, eccentricity, type of soil under the footing, frost depth etc. there is no possibility of making one proper numerical analysis and optimization to cover all possible schemes and scenarios. According to that, numerical analyzes should have been performed after the geological investigation and design of supported structure. Only in that case it could be possible to properly optimize footings in order to reduce its costs of casting and maximize utilization of ground conditions.

\section{Conclusion}

In this paper a new type of innovative solution of socket footing was proposed. The innovative solution concerned the connection between column and footing. In typical socket footings connection is made by columns' and footings' socket planar end, where sometimes in the socket centering bolt for the column is used. In the proposed solution footings' socket was ended as a cut-off pyramid. According to that, column which would be connected with the footing also should have prepared cutoff pyramid on its one end, however the cut-off should be realized few centimeters higher comparing to footing cut-off in order to provide some free space. Such solution not only allow to easier centering the column, but also provides the possibility to reduce the footing dimensions in comparison to typical socket footing, while keeping the same value of stress under the base. The reduction of footings' dimensions was possible, due to different forces distribution comparing to the typical socket footing, where mostly compressive force is transferred onto the footing and in consequence onto the ground. In the proposed solution some amount of compressive force from the column was transformed into tensile force acting in the footing due to provided special gap. According to that more complex rebar reinforcement would be required. In order to strengthen the areas near column and footing connection as well as to minimize the effort of forming such complex shape of socket, special steel casted forms could be used. One of the forms could be used to form the socket shape by embedding it into the footing or weld to the existing steel reinforcement and then fill the framework with the concrete mix and one would be used to form columns' end. Moreover, such forms would prevent concrete cracking near the connection under the influence of load eccentricity.

For the proposed solution numerical analysis concerning the stresses in the column, connection forms, foundation and under the footing base was performed. It was shown that for pure axial loading in the proposed socket footing stress under the base was approximately two times lower than for typical socket foundation. With greater value of load eccentricity, stresses under the footing in both cases tend to be closer. Through the analysis it was additionally shown that for the load of $500 \mathrm{kN}$ applied on eccentricity higher than $0.40 \mathrm{~m}$, stress in the column and footing near the connection exceeded the value of assumed C20/25 concrete class compressive strength. In the steel forms stresses were far beyond the maximum of $235 \mathrm{MPa}$ for S235JR grade steel in the whole range of load eccentricity $0 \leq e \leq 0.80 \mathrm{~m}$.

Additionally, due to the fact, that the stress under the base in case of typical socket footing was greater than in the proposed one, optimization process of height and footing area reduction was performed. It was shown that keeping the width dimension of $2.50 \mathrm{~m}$ total height of footing could be reduced by $0.25 \mathrm{~m}$ to obtain approximately the same level of stress as for typical socket footing. In the second analysis, where only width dimensions of footing were modified while keeping the total height of $1.40 \mathrm{~m}$ it was shown, that the footing base could be reduced to the square with $1.00 \mathrm{~m}$ edge length. It should be noted, that for pure axial loading, the width dimension could be furtherly reduced, however in order to provide appropriate support for the column and nominal reinforcement coverage square 
with $1.00 \times 1.00 \mathrm{~m}$ was assumed as minimal. Presented in paper optimization graphs should help to choose the right height and footing base dimensions to obtain approximately required stress in case of similarly supported and loaded footing.

In the second optimization study, footing extrusion in the direction of eccentricity was analyzed in order to counteract the effect of rotation under the eccentric loading. It was shown that the eccentricity effect can be completely reduced - footing could be evenly imbedded. Despite that with greater footing width dimension, leaving the second dimension unmodified lead to increased value of MHM stress under the footing base due to increased footing weight as well as greater soil stiffness preventing the footing to rotate. It should be noted that presented in paper analyses cover only small variety of different parameters - only one external shape of footing and one value of applied load for only non-cohesive medium grain sand was considered. According to that further analyses should have been performed, covering other type of soils, footings external shapes and types of loading.

Finite element method based software is a very powerful tool. Numerical analyses may cover almost all areas of life i.e. analyses are performed in medicine, civil engineering, mechanical engineering, automotive industry, aeronautics, meteorology etc. Recently, numerical analyses are also performed in product design [18 - 20], for example, some running shoes manufacturers perform numerical analyses to improve the comfort and reduce the shock with each step during running.

Despite the positive aspects of numerical analyses, it should be noted that experimental test should have also been carried-out. If only assumed conditions and obtained results are confirmed within real test, product or structure can be introduced into production. Knowing that the presented in this paper footing with pyramid ended socket was a concept solution, before the production, experimental tests would be required.

\section{References}

[1] PRZEWŁÓCKI, J. - DARDZIŃSKA, I. - ŚWINIAŃSKI, J.: Review of historical buildings' foundations. Geotechnique, Vol. 55, No. 5, 2005, pp. 363 - 372.

[2] PN-EN 1992-1-1:2008/Ap1:2010, Eurocode 2: Concrete constructions design procedures, Part 1-1: General requirements and requirements for buildings, PKN, Warszawa 2008 (in Polish).

[3] PN-EN 1997-1:2008, Eurocode 7: Geotechnical design, Part 1: General rules, PKN, Warszawa 2008 (in Polish).

[4] KNAUFF, M. - KNYZIAK, P. - GOLUBIŃSKA, A.: Tables and equations for the design of reinforced concrete elements with calculations examples. Second edition, PWN, Warszawa 2014, 443 p. (in Polish).

[5] STAROSOLSKI, W.: Reinforced concrete structures in reference to Eurocode 2 and other national standards. Vol. 3, PWN, Warszawa 2012, 682 p. (in Polish).

[6] KREJSA, M. - BROZOVSKY, J. - MIKOLASEK, D. - PARENICA, P. - FLODR, J. - MATERNA, A. - HALAMA, R. - KOZAK, J.: Numerical modelling of steel fillet welded joint. Advances in Engineering Software, Vol. 117, 2018, pp. 59 - 69.

[7] KORMANIKOVA, E. - KOTRASOVÁ, K.: Finite Element Analysis of Damage Modelling of Fiber Reinforced Laminate Plate. Applied Mechanics and Materials, Vol. 617, 2014, pp. 247 - 250.

[8] LUO, N. - BATHURST, R. J.: Reliability bearing capacity analysis of footings on cohesive soil slopes using RFEM. Computers and Geotechnics, Vol. 89, 2017, pp. 203 - 212.

[9] MOAYEDI, H. - HAYATI, S.: Modelling and optimization of ultimate bearing capacity of strip footing near a slope by soft computing methods. Applied Soft Computing, Vol. 66, 2018, pp. 208 - 219.

[10] JAVID, A. H. - FAHIMIFAR, A. - IMANI, M.: Numerical investigation on the bearing capacity of two interfering strip footings resting on a rock mass. Computers and Geotechnics, Vol. 69, 2015, pp. $514-528$.

[11] MABROUKI, A. - BENMEDDOUR, D. - FRANK, R. - MELLAS, M.: Numerical study of the bearing capacity for two interfering strip footings on sands. Computers and Geotechnics, Vol. 37, No. 4, 2010, pp. 431 - 439.

[12] LOUKIDIS, D. - SALGADO, R.: Bearing capacity of strip and circular footings in sand using finite elements. Computers and Geotechnics, Vol. 36, No. 5, 2009, pp. 871 - 879.

[13] BENMEBAREK, S. - REMADNA, M. S. - BENMEBAREK, N. - BELOUNAR, L.: Numerical evaluation of the bearing capacity factor $N_{\gamma}^{\prime}$ of ring footings. Computers and Geotechnics, Vol. 44, 2012, pp. $132-138$.

[14] MAJOR, M. - KULIŃSKI, K. - MAJOR, I.: Dynamic analysis of an impact load applied to the composite wall structure. MATEC Web of Conferences, Vol. 107, 2017, pp. 1 - 6. 
[15] MAJOR, M. - KULIŃSKI, K. - MAJOR, I.: Innovative concrete-polyurethane composite blocks located in three-layer wall - thermal numerical analysis. Engineering Mechanics (red.) FUIS Vladimir, Brno, 2017, pp. $602-605$.

[16] BADAKHSHAN, E. - NOORZAD, A.: Load eccentricity effects on behavior of circular footings reinforced with geogrid sheets. Journal of Rock Mechanics and Geotechnical Engineering, Vol. 7, No. 6, 2015, pp. $691-699$.

[17] SHARMA, V. - KUMAR, A.: Behavior of ring footing resting on reinforced sand subjected to eccentric-inclined loading. Journal of Rock Mechanics and Geotechnical Engineering, Vol. 10, No. 2, 2018, pp. $347-357$.

[18] CHEUNG, J. T. M. - ZHANG, M.: Finite element modelling of the human foot and footwear. ABAQUS Users' Conference, 2006, pp. 145 - 159.

[19] KOIKE, S. - OKINA, S.: A modelling method of sport shoes for dynamic analysis of shoe-body coupled system. Procedia Engineering, Vol. 34, 2012, pp. 272 - 277.

[20] CHO, J. R. - PARK, S. B. - RYU, S. H. - KIM, S. H. - LEE, S. B.: Landing impact analysis of sport shoes using 3-D coupled foot-shoe finite element model. Journal of Mechanical Science and Technology, Vol. 23, 2009, pp. 2583 - 2591. 